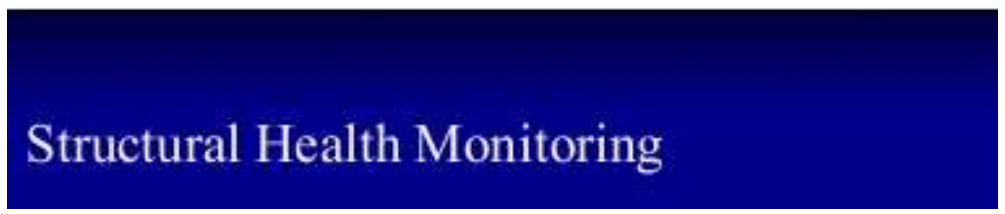

\title{
LMS-based approach to structural health monitoring of nonlinear hysteretic structures
}

\begin{tabular}{|r|l|}
\hline Journal: & Structural Health Monitoring \\
\hline Manuscript ID: & SHM-10-0030.R1 \\
\hline Manuscript Type: & Original Manuscript \\
\hline Author: & n/a \\
\hline Complete List of Authors: & $\begin{array}{l}\text { Nayyerloo, Mostafa; University of Canterbury, Mechanical } \\
\text { Engineering Dept. } \\
\text { Chase, J. Geoffrey; University of Canterbury, Mechanical } \\
\text { Engineering Dept. } \\
\text { MacRae, Gregory; University of Canterbury, Civil and Natural } \\
\text { Resources Engineering Dept. } \\
\text { Chen, XiaoQi; University of Canterbury, Mechanical Engineering } \\
\text { Dept. }\end{array}$ \\
\hline Keywords: & $\begin{array}{l}\text { structural health monitoring (SHM), structural identification, } \\
\text { damage detection, nonlinear hysteretic structures, the Bouc-Wen } \\
\text { model, adaptive LMS filters }\end{array}$ \\
\hline Abstract: & $\begin{array}{l}\text { Structural health monitoring (SHM) algorithms based on adaptive } \\
\text { Least Mean Squares (LMS) filtering theory can directly identify } \\
\text { time-varying changes in structural stiffness in real-time in a } \\
\text { computationally efficient fashion. However, better metrics of } \\
\text { seismic structural damage and future utility after an event are } \\
\text { related to permanent and total plastic deformations. This paper } \\
\text { presents a modified LMS-based SHM method and a novel two-step } \\
\text { structural identification technique using a baseline nonlinear Bouc- } \\
\text { Wen structural model to directly identify changes in stiffness due to } \\
\text { damage, as well as plastic or permanent deflections. The algorithm } \\
\text { is designed to be computationally efficient; therefore it can work in } \\
\text { real-time. An in silico single-degree-of-freedom (SDOF) nonlinear } \\
\text { shear-type structure is used to prove the concept. The efficiency of } \\
\text { the proposed SHM algorithm in identifying stiffness changes and } \\
\text { plastic/permanent deflections is assessed under different ground } \\
\text { motions using a suite of 20 different ground acceleration records. } \\
\text { The results show that in a realistic scenario with fixed filter tuning } \\
\text { parameters, the proposed LMS-based SHM algorithm identifies } \\
\text { stiffness changes to within 10\% of true values within 2.0 seconds. } \\
\text { Permanent deflection is identified to within 14\% of the actual as- } \\
\text { modelled value using noise-free simulation-derived structural } \\
\text { responses. This latter value provides important post-event }\end{array}$ \\
\hline and
\end{tabular}


1

2

3

4

5

6

7

8

9

10

11

12

13

14

15

16

17

18

19

20

21

22

23

24

25

26

27

28

29

30

31

32

33

34

35

36

37

38

39

40

41

42

43

44

45

46

47

48

49

50

51

52

53

54

55

56

57

58

59

60 information on the future serviceability, safety, and repair cost.

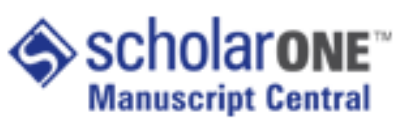




\title{
LMS-based approach to structural health monitoring of nonlinear hysteretic structures
}

\author{
M. Nayyerloo ${ }^{1, *, \dagger}$, J. G. Chase ${ }^{1}$, G. A. MacRae ${ }^{2}$ and X.-Q. Chen ${ }^{1}$ \\ ${ }^{1}$ Department of Mechanical Engineering, University of Canterbury, Private Bag 4800, \\ Christchurch 8140, New Zealand \\ ${ }^{2}$ Department of Civil and Natural Resources Engineering, University of Canterbury, Private \\ Bag 4800, Christchurch 8140, New Zealand
}

\section{SUMMARY}

Structural health monitoring (SHM) algorithms based on adaptive Least Mean Squares (LMS) filtering theory can directly identify time-varying changes in structural stiffness in realtime in a computationally efficient fashion. However, better metrics of seismic structural damage and future utility after an event are related to permanent and total plastic deformations. This paper presents a modified LMS-based SHM method and a novel two-step structural identification technique using a baseline nonlinear Bouc-Wen structural model to directly identify changes in stiffness due to damage, as well as plastic or permanent deflections. The algorithm is designed to be computationally efficient; therefore it can work in real-time. An in silico single-degree-of-freedom (SDOF) nonlinear shear-type structure is used to prove the concept. The efficiency of the proposed SHM algorithm in identifying stiffness changes and plastic/permanent deflections is assessed under different ground motions using a suite of 20 different ground acceleration records. The results show that in a realistic scenario with fixed filter tuning parameters, the proposed LMS-based SHM algorithm identifies stiffness changes to within $10 \%$ of true values within 2.0 seconds. Permanent deflection is identified to within $14 \%$ of the actual as-modelled value using noise-free simulation-derived structural responses. This

\footnotetext{
* Correspondence to: M. Nayyerloo, Department of Mechanical Engineering, University of Canterbury, Private Bag 4800, Christchurch 8140, New Zealand.

Phone: +64-3-3642987 Extension: 7358

Fax: +64-3-364 2078

†E-mail: mostafa.nayyerloo@pg.canterbury.ac.nz and m.nayyerloo@gmail.com
} 
1

latter value provides important post-event information on the future serviceability, safety, and repair cost.

KEY WORDS: structural health monitoring (SHM), structural identification, damage detection, nonlinear hysteretic structures, the Bouc-Wen model, adaptive LMS filters.

\section{INTRODUCTION}

Structural health monitoring (SHM) is the process of comparing the current state of a structure's condition relative to a baseline state to detect the existence, location, and degree of likely damage after a damaging input, such as an earthquake. SHM can simplify and improve typical visual or localized experimental approaches, as it does not require subjective visual inspection of the structure [1]. It can thus provide valuable data for post-event safety assessments to help optimize recovery planning.

Many current vibration-based SHM methods are based on the idea that changes in modal parameters; frequencies, mode shapes and modal damping, are a result of damage or decay [2]. These methods are typically more applicable to steel-frame and bridge structures where vibration response is highly linear [2, 3]. Wavelet approaches offer a similar approach, as well as determining the time at which damage occurred [4]. A major drawback of many approaches is their inability to be implemented in real-time, on a sample-to-sample basis as the event occurs. Hence, these methods are not suitable for real-time structural control for damage reduction purposes, and their results would not be immediately available after an event. Further, their reliance on modal properties has potential problems as modal properties are not robust in the presence of noise and do not always represent measurable damage [4]. 
Adaptive fading Kalman filters [5, 6], adaptive $\mathrm{H}_{\infty}$ filter techniques [7], and bootstrap filtering approaches [8] can achieve real-time or near real-time results and provide structural parameter identification. However, they have significant computational cost and complexity. Simpler and more suitable algorithms for on-line SHM make use of Least Squares Estimation (LSE) [3, 914] with different stochastic gradient estimation approaches.

Model-based methods combined with adaptive Least Mean Squares (LMS) filtering theory offer the opportunity of identifying stiffness changes in real-time in a computationally efficient and robust fashion. LMS-based SHM has been used for a benchmark problem [3], and also for a highly nonlinear rocking structure [14], to directly identify changes in structural stiffness only. Similar Recursive Least Squares (RLS) methods have also been applied to the same problem [13]. These model-based adaptive filtering methods are robust with fast convergence and low computational cost. However, they do not identify plastic and permanent deflections, and require full state structural response measurement.

The article develops a modified adaptive LMS-based SHM method using the nonlinear Bouc-Wen structural baseline model to directly identify both changes in stiffness and plastic deflections in real-time. A novel computationally-efficient structural identification method with two steps is presented that assumes limited a priori knowledge of the structure's potential nonlinear behaviour based on readily available design information. The effect of the specific external load on performance of the proposed SHM method is evaluated using a suite of 20 different ground motions to test robustness of the results. The noise effect on the results is accounted for at later stages of this study. 


\section{DEFINITION OF THE SHM PROBLEM}

A seismically excited nonlinear structure can be modelled at each time step using incremental equations of motion:

$$
\mathbf{M} \cdot\{\Delta \ddot{v}\}+\mathbf{C} \cdot\{\Delta \dot{v}\}+\mathbf{K}_{\mathbf{T}}(\mathbf{t}) \cdot\{\Delta v\}=-\underline{\mathbf{M}} \cdot \Delta \ddot{x}_{g}
$$

where $\mathbf{M}, \mathbf{C}$, and $\mathbf{K}_{\mathbf{T}}$ are the mass, damping, and tangent stiffness matrices of the model, respectively, $\{\Delta v\},\{\Delta \dot{v}\}$, and $\{\Delta \ddot{v}\}$ are the changes in displacement, velocity, and acceleration vectors, respectively, and $\ddot{x}_{g}$ is the change in the ground motion acceleration over the time step.

The tangent stiffness matrix of a hysteretic structure can be represented using the Bouc-Wen model $[15,16]$. For instance, the tangent stiffness matrix of a four-degree-of-freedom (4-DOF) four-storey shear-type structure, as an example for the tangent stiffness matrix of a hysteretic structure in multi-degreeof-freedom (MDOF) case, can be written: 


$$
\begin{aligned}
& \left(\mathbf{K}_{\mathrm{T}}\right)_{11}=\left[\alpha_{1}+\left(1-\alpha_{1}\right) Y_{1} \frac{\Delta z_{1}}{\Delta v_{1}}\right]\left(k_{0}\right)_{1}+\alpha_{2}\left(k_{0}\right)_{2} \\
& \left(\mathbf{K}_{\mathrm{T}}\right)_{12}=-\left[\alpha_{2}+\left(1-\alpha_{2}\right) Y_{2} \frac{\Delta z_{2}}{\Delta v_{2}}\right]\left(k_{0}\right)_{2} \\
& \left(\mathbf{K}_{\mathrm{T}}\right)_{21}=-\alpha_{2}\left(k_{0}\right)_{2} \\
& \left(\mathbf{K}_{\mathrm{T}}\right)_{22}=\left[\alpha_{2}+\left(1-\alpha_{2}\right) Y_{2} \frac{\Delta z_{2}}{\Delta v_{2}}\right]\left(k_{0}\right)_{2}+\alpha_{3}\left(k_{0}\right)_{3} \\
& \left(\mathbf{K}_{\mathrm{T}}\right)_{23}=-\left[\alpha_{3}+\left(1-\alpha_{3}\right) Y_{3} \frac{\Delta z_{3}}{\Delta v_{3}}\right]\left(k_{0}\right)_{3} \\
& \left(\mathbf{K}_{\mathrm{T}}\right)_{32}=-\alpha_{3}\left(k_{0}\right)_{3} \\
& \left(\mathbf{K}_{\mathrm{T}}\right)_{33}=\left[\alpha_{3}+\left(1-\alpha_{3}\right) Y_{3} \frac{\Delta z_{3}}{\Delta v_{3}}\right]\left(k_{0}\right)_{3}+\alpha_{4}\left(k_{0}\right)_{4} \\
& \left(\mathbf{K}_{\mathrm{T}}\right)_{34}=-\left[\alpha_{4}+\left(1-\alpha_{4}\right) Y_{4} \frac{\Delta z_{4}}{\Delta v_{4}}\right]\left(k_{0}\right)_{4} \\
& \left(\mathbf{K}_{\mathrm{T}}\right)_{43}=-\alpha_{4}\left(k_{0}\right)_{4} \\
& \left(\mathbf{K}_{\mathrm{T}}\right)_{44}=\left[\alpha_{4}+\left(1-\alpha_{4}\right) Y_{4} \frac{\Delta z_{4}}{\Delta v_{4}}\right]\left(k_{0}\right)_{4} \\
& \left(\mathbf{K}_{\mathrm{T}}\right)_{13}=\left(\mathbf{K}_{\mathrm{T}}\right)_{14}=\left(\mathbf{K}_{\mathrm{T}}\right)_{24}=\left(\mathbf{K}_{\mathrm{T}}\right)_{31}=\left(\mathbf{K}_{\mathrm{T}}\right)_{41}=\left(\mathbf{K}_{\mathrm{T}}\right)_{42}=0
\end{aligned}
$$

where $\left(\mathbf{K}_{\mathbf{T}}\right)_{\mathrm{ij}}, i, j=1, \ldots, 4$, are components of the $4 \times 4$ tangent stiffness matrix, $0 \leq \alpha_{i} \leq 1, i=1, \ldots, 4$, is the $i^{\text {th }}$ storey bi-linear factor, which determines the change in slope between elastic and plastic regimes of that storey $\left(\alpha_{i}=0\right.$ represents a fully hysteretic and $\alpha_{i}=1$ a fully elastic structure.), and $z_{i}, i=1, \ldots, 4$, is the dimensionless hysteretic component of the $i^{\text {th }}$ storey and is governed by the following first order nonlinear differential equation $[17,18]$ :

$$
\begin{aligned}
& \dot{z}_{i}(t)=\frac{A_{i} \dot{r}_{i}(t)-\beta_{i}\left|\dot{r}_{i}(t)\right|\left|z_{i}(t)\right|^{n_{i}-1} z_{i}(t)-\gamma_{i} \dot{r}_{i}(t)\left|z_{i}(t)\right|^{n_{i}}}{Y_{i}} \\
& A_{i}>0, \beta_{i}>0,-\beta_{i} \leq \gamma_{i} \leq \beta_{i}, n_{i}>0 \\
& i=1, \ldots, N
\end{aligned}
$$

where $A_{i}$ (usually 1.0$), \beta_{i}$ (0.1 to 0.9$), \gamma_{i}(-0.9$ to 0.9$)$, and $n_{i}$ (1 to 3 , usually 1 ) are stiffness, loop fatness, loop pinching, and abruptness parameters in the classical Bouc-Wen model, respectively. Further, $n_{i}$, the power factor, determines the sharpness of the curve from elastic to plastic force-deflection behaviour of each storey. Finally, $\dot{r}_{i}(t)$ is the velocity of storey $i$ relative to 
storey $i-1, Y_{i}$ is the yield displacement of $i^{\text {th }}$ story, and $N$ is the number of stories in a shear-type structure. The five dimensionless parameters, $A_{i}, \beta_{i}, \gamma_{i}, n_{i}$, and $\alpha_{i}$ determine the hysteresis loop shape. Detailed information on the Bouc-Wen model can be found in an excellent review by Ismail et al. [18].

Neither degradation nor pinching of hysteresis is accounted for by the classical Bouc-Wen model. Over the years, this classical model has been modified to a contemporary model to accommodate changes in hysteresis loops arising from deteriorating systems [19]. In this study, the classical Bouc-Wen model in conjunction with a variable structural stiffness has been used to model nonlinearities arising from both the hysteretic behaviour of the structure and degradation. However, with more a priori knowledge, the more detailed contemporary model could be used.

Since the Bouc-Wen model captures dominant energy dissipation due to nonlinear behaviour, structural damage may be assessed by its impact on stiffness and plastic deformations over time. The potentially time-varing equations of motion for a damaged structure can be defined:

$$
\mathbf{M} \cdot\{\Delta \ddot{\bar{v}}\}+\mathbf{C} \cdot\{\Delta \dot{\bar{v}}\}+\left(\overline{\mathbf{K}}_{\mathbf{T}}(\mathbf{t})+\Delta \overline{\mathbf{K}}_{\mathbf{T}}(\mathbf{t})\right) \cdot\{\Delta \bar{v}\}=-\underline{\mathbf{M}} \cdot \Delta \ddot{x}_{g}
$$

where $\{\Delta \ddot{\bar{v}}\},\{\Delta \dot{\bar{v}}\}$, and $\{\Delta \bar{v}\}$ are the measured changes in responses of the damaged structure, $\overline{\mathbf{K}}_{\mathrm{T}}$, is the tangent stiffness matrix of the damaged structure from Equation (2) using damaged structural responses, and $\Delta \overline{\mathbf{K}}_{\mathrm{T}}(\mathbf{t})$ contains changes in the tangent stiffness of the structure due to damage and can be a function of time. Using the Bouc-Wen model of Equation (2), $\Delta \overline{\mathbf{K}}_{\mathbf{T}}$ can be written: 


$$
\begin{aligned}
& \left(\Delta \overline{\mathbf{K}}_{\mathrm{T}}\right)_{11}=\left[\alpha_{1}+\left(1-\alpha_{1}\right) Y_{1} \frac{\Delta \bar{z}_{1}}{\Delta \bar{v}_{1}}\right]\left(\Delta k_{0}\right)_{1}+\alpha_{2}\left(\Delta k_{0}\right)_{2} \\
& \left(\Delta \overline{\mathbf{K}}_{\mathrm{T}}\right)_{12}=-\left[\alpha_{2}+\left(1-\alpha_{2}\right) Y_{2} \frac{\Delta \bar{z}_{2}}{\Delta \bar{v}_{2}}\right]\left(\Delta k_{0}\right)_{2} \\
& \left(\Delta \overline{\mathbf{K}}_{\mathrm{T}}\right)_{21}=-\alpha_{2}\left(\Delta k_{0}\right)_{2} \\
& \left(\Delta \overline{\mathbf{K}}_{\mathbf{T}}\right)_{22}=\left[\alpha_{2}+\left(1-\alpha_{2}\right) Y_{2} \frac{\Delta \bar{z}_{2}}{\Delta \bar{v}_{2}}\right]\left(\Delta k_{0}\right)_{2}+\alpha_{3}\left(\Delta k_{0}\right)_{3} \\
& \left(\Delta \overline{\mathbf{K}}_{\mathbf{T}}\right)_{23}=-\left[\alpha_{3}+\left(1-\alpha_{3}\right) Y_{3} \frac{\Delta \bar{z}_{3}}{\Delta \bar{v}_{3}}\right]\left(\Delta k_{0}\right)_{3} \\
& \left(\Delta \overline{\mathbf{K}}_{\mathrm{T}}\right)_{32}=-\alpha_{3}\left(\Delta k_{0}\right)_{3} \\
& \left(\Delta \overline{\mathbf{K}}_{\mathbf{T}}\right)_{33}=\left[\alpha_{3}+\left(1-\alpha_{3}\right) Y_{3} \frac{\Delta \bar{z}_{3}}{\Delta \bar{v}_{3}}\right]\left(\Delta k_{0}\right)_{3}+\alpha_{4}\left(\Delta k_{0}\right)_{4} \\
& \left(\Delta \overline{\mathbf{K}}_{\mathbf{T}}\right)_{34}=-\left[\alpha_{4}+\left(1-\alpha_{4}\right) Y_{4} \frac{\Delta \bar{z}_{4}}{\Delta \bar{v}_{4}}\right]\left(\Delta k_{0}\right)_{4} \\
& \left(\Delta \overline{\mathbf{K}}_{\mathbf{T}}\right)_{43}=-\alpha_{4}\left(\Delta k_{0}\right)_{4} \\
& \left(\Delta \overline{\mathbf{K}}_{\mathbf{T}}\right)_{44}=\left[\alpha_{4}+\left(1-\alpha_{4}\right) Y_{4} \frac{\Delta \bar{z}_{4}}{\Delta \bar{v}_{4}}\right]\left(\Delta k_{0}\right)_{4} \\
& \left(\Delta \overline{\mathbf{K}}_{\mathbf{T}}\right)_{13}=\left(\Delta \overline{\mathbf{K}}_{\mathbf{T}}\right)_{14}=\left(\Delta \overline{\mathbf{K}}_{\mathrm{T}}\right)_{24}=\left(\Delta \overline{\mathbf{K}}_{\mathrm{T}}\right)_{31}=\left(\Delta \overline{\mathbf{K}}_{\mathbf{T}}\right)_{41}=\left(\Delta \overline{\mathbf{K}}_{\mathbf{T}}\right)_{42}=0
\end{aligned}
$$

Identifying the $\Delta \overline{\mathbf{K}}_{\mathrm{T}}$ term enables the structure's condition including any plastic/permanent deformation to be directly monitored.

To determine $\Delta \overline{\mathbf{K}}_{\mathrm{T}}$ using adaptive LMS methods, a new form of $\Delta \overline{\mathbf{K}}_{\mathrm{T}}$ is defined with time-varying scalar parameters $\hat{\alpha}_{i}$, to be identified using the LMS filter based on $[3,13,14]$. For a 4-DOF four-story example shear building $\Delta \overline{\mathbf{K}}_{\mathrm{T}}$ can be sub-divided into four matrices to allow independent identification of changes in the linear elastic stiffness component of each story i.e. $\left(\Delta k_{0}\right)_{1},\left(\Delta k_{0}\right)_{2}$, $\left(\Delta k_{0}\right)_{3}$, and $\left(\Delta k_{0}\right)_{4}$ :

$$
\Delta \overline{\mathbf{K}}_{\mathbf{T}}=\hat{\alpha}_{1} \mathbf{K}_{\mathbf{1}}+\hat{\alpha}_{2} \mathbf{K}_{\mathbf{2}}+\hat{\alpha}_{3} \mathbf{K}_{\mathbf{3}}+\hat{\alpha}_{4} \mathbf{K}_{\mathbf{4}}
$$

where, 


$$
\begin{aligned}
& \mathbf{K}_{1}=\left[\begin{array}{cccc}
\alpha_{1}+\left(1-\alpha_{1}\right) Y_{1} \frac{\Delta \bar{z}_{1}}{\Delta \bar{v}_{1}} & 0 & 0 & 0 \\
0 & 0 & 0 & 0 \\
0 & 0 & 0 & 0 \\
0 & 0 & 0 & 0
\end{array}\right] \\
& \mathbf{K}_{2}=\left[\begin{array}{cccc}
\alpha_{2} & -\left[\alpha_{2}+\left(1-\alpha_{2}\right) Y_{2} \frac{\Delta \bar{z}_{2}}{\Delta \bar{v}_{2}}\right] & 0 & 0 \\
-\alpha_{2} & \alpha_{2}+\left(1-\alpha_{2}\right) Y_{2} \frac{\Delta \bar{z}_{2}}{\Delta \bar{v}_{2}} & 0 & 0 \\
0 & 0 & 0 & 0 \\
0 & 0 & 0 & 0
\end{array}\right] \\
& \mathbf{K}_{3}=\left[\begin{array}{cccc}
0 & 0 & 0 & 0 \\
0 & \alpha_{3} & -\left[\alpha_{3}+\left(1-\alpha_{3}\right) Y_{3} \frac{\Delta \bar{z}_{3}}{\Delta \bar{v}_{3}}\right. & 0 \\
0 & -\alpha_{3} & \alpha_{3}+\left(1-\alpha_{3}\right) Y_{3} \frac{\Delta \bar{z}_{3}}{\Delta \bar{v}_{3}} & 0 \\
0 & 0 & 0 & 0
\end{array}\right] \\
& \mathbf{K}_{4}=\left[\begin{array}{cccc}
0 & 0 & 0 & 0 \\
0 & 0 & 0 & 0 \\
0 & 0 & \alpha_{4} & -\left[\alpha_{4}+\left(1-\alpha_{4}\right) Y_{4} \frac{\Delta \bar{z}_{4}}{\Delta \bar{v}_{4}}\right] \\
0 & 0 & -\alpha_{4} & \alpha_{4}+\left(1-\alpha_{4}\right) Y_{4} \frac{\Delta \bar{z}_{4}}{\Delta \bar{v}_{4}}
\end{array}\right]
\end{aligned}
$$

and

$$
\hat{\alpha}_{1}=\left(\Delta k_{0}\right)_{1}, \hat{\alpha}_{2}=\left(\Delta k_{0}\right)_{2}, \hat{\alpha}_{3}=\left(\Delta k_{0}\right)_{3}, \hat{\alpha}_{4}=\left(\Delta k_{0}\right)_{4}
$$

Hence, Equations (6)-(11) can be summarised:

$$
\Delta \overline{\mathbf{K}}_{\mathbf{T}}=\sum_{i=1}^{n} \hat{\alpha}_{i} \mathbf{K}_{\mathbf{i}}
$$


where $n$ is the number of degrees of freedom of the model, and $\mathbf{K}_{\mathbf{i}}$ is the corresponding time-varying matrix to $i^{\text {th }}$ DOF in Equations (6)-(10). Rewriting Equation (4) using Equations (6)-(12) yields:

$$
\sum_{i=1}^{n} \hat{\alpha}_{i} \mathbf{K}_{\mathbf{i}} \cdot\{\Delta \bar{v}\}=-\underline{\mathbf{M}} \cdot \Delta \ddot{x}_{g}-\mathbf{M} \cdot\{\Delta \ddot{\bar{v}}\}-\mathbf{C} \cdot\{\Delta \dot{\bar{v}}\}-\overline{\mathbf{K}}_{\mathbf{T}} \cdot\{\Delta \bar{v}\}
$$

where $\{\Delta \ddot{\bar{v}}\},\{\Delta \dot{\bar{v}}\}$, and $\{\Delta \bar{v}\}$ are measured, and $\overline{\mathbf{K}}_{\mathbf{T}}$ at each time step is calculated using Equations (2) and (3). To this end, the $Y_{i} \Delta \bar{z}_{i}$ term in $\overline{\mathbf{K}}_{\mathrm{T}}$ and the $\mathbf{K}_{\mathbf{i}}$ matrices can be re-defined by introducing a hysteretic displacement, $h_{i}$, for each storey defined:

$$
h_{i}=Y_{i} z_{i}, i=1, \ldots, N
$$

where $Y_{i}$ and $z_{i}$ are the yield displacement and the hysteretic component of the $i^{\text {th }}$ storey, respectively. Therefore, Equation (3) can be rewritten:

$$
\dot{h}_{i}(t)=\dot{r}_{i}(t)\left\{A_{i}-\beta_{i} \frac{\left|\dot{r}_{i}(t)\right|}{\dot{r}_{i}(t)}\left|\frac{h_{i}(t)}{Y_{i}}\right|^{n_{i}-1} \frac{h_{i}(t)}{Y_{i}}-\gamma_{i}\left|\frac{h_{i}(t)}{Y_{i}}\right|^{n_{i}}\right\}, i=1, \ldots, N
$$

which is equivalent to:

$$
\dot{h}_{i}(t)=\dot{r}_{i}(t)\left\{A_{i}-\left|\frac{h_{i}(t)}{Y_{i}}\right|^{n_{i}}\left(\beta_{i} \frac{\left|\dot{r}_{i}(t)\right|}{\dot{r}_{i}(t)} \frac{h_{i}(t)}{\left|h_{i}(t)\right|}+\gamma_{i}\right)\right\}, i=1, \ldots, N
$$

where: 


$$
\frac{\left|\dot{r}_{i}(t)\right|}{\dot{r}_{i}(t)} \frac{h_{i}(t)}{\left|h_{i}(t)\right|}=\operatorname{sign}\left(\dot{r}_{i}(t) h_{i}(t)\right), i=1, \ldots, N
$$

yielding,

$$
\dot{h}_{i}(t)=\dot{r}_{i}(t)\left\{A_{i}-\left|\frac{h_{i}(t)}{Y_{i}}\right|^{n_{i}}\left(\beta_{i} \operatorname{sign}\left(\dot{r}_{i}(t) h_{i}(t)\right)+\gamma_{i}\right)\right\}, i=1, \ldots, N
$$

Using Equation (18) and assuming constant $\dot{h}_{i}$ over the small interval $(\Delta t)$ for each time step, the changes in hysteretic displacement of storey $i$ over each time step, $\Delta h_{i}=Y_{i} \Delta z_{i}$, are defined:

$$
\begin{aligned}
& h_{i}(t+\Delta t)-h_{i}(t)=\dot{r}_{i}(t)\left\{A_{i}-\left|\frac{h_{i}(t)}{Y_{i}}\right|^{n_{i}}\left(\beta_{i} \operatorname{sign}\left(\dot{r}_{i}(t) h_{i}(t)\right)+\gamma_{i}\right)\right\} \Delta t \\
& i=1, \ldots, N
\end{aligned}
$$

Therefore, $\Delta \bar{h}_{i}=Y_{i} \Delta \bar{z}_{i}$, changes in damaged hysteretic displacement of $i^{\text {th }}$ storey over each time step, can be determined from Equation (19) using measured or estimated damaged structural responses, $\{\Delta \ddot{\bar{v}}\},\{\Delta \dot{\bar{v}}\}$, and $\{\Delta \bar{v}\}$.

The damaged structure stiffness, or effective stiffness changes due to nonlinear behaviour, can then be determined by identifying the $\hat{\alpha}_{i}$ in Equation (13) at every time step [3]:

$$
\{y\}_{k}=\sum_{i=1}^{n} \hat{\alpha}_{i} \mathbf{K}_{\mathbf{i}} \cdot\{\Delta \bar{v}\}_{k}=-\mathbf{M} \cdot\left(\Delta \ddot{x}_{g}\right)_{k}-\mathbf{M} \cdot\{\Delta \ddot{\bar{v}}\}_{k}-\mathbf{C} \cdot\{\Delta \dot{\bar{v}}\}_{k}-\overline{\mathbf{K}}_{\mathbf{T}} \cdot\{\Delta \bar{v}\}_{k}
$$


where $\left(\Delta \ddot{x}_{g}\right)_{k}$ is the change in the input ground acceleration over a given time step of $k$, and $\{\Delta \ddot{\bar{v}}\}_{k},\{\Delta \dot{\bar{v}}\}_{k}$, and $\{\Delta \bar{v}\}_{k}$ are the measured changes in the acceleration, velocity, and displacement vectors of the damaged structure over the same time step, respectively. Matrices $\overline{\mathbf{K}}_{\mathbf{T}}$ and $\mathbf{K}_{\mathbf{i}}$ are calculated sample-tosample using Equations (2) and (7)-(10) with the measured damaged structural responses. The elements of the vector signal $\{y\}_{k}$ can be readily modelled in real-time using adaptive LMS filters to identify the coefficients $\hat{\alpha}_{i}$ reflecting changes in linear stiffness of each storey [3].

Plastic displacements can also be calculated using the Bouc-Wen model. As Figure 1 illustrates, the plastic displacement range of storey $i$ relative to storey $i-1$ during a stable hysteresis loop, $\Delta\left(r_{p}\right)_{i}(t)$, can be written [20]:

$$
\Delta\left(r_{p}\right)_{i}(t)=\Delta r_{i}(t)-\Delta\left(r_{e}\right)_{i}(t)=\Delta r_{i}(t)-\frac{\Delta\left(F_{r}\right)_{i}(t)}{\left(k_{0}\right)_{i}}, i=1, \ldots, N
$$

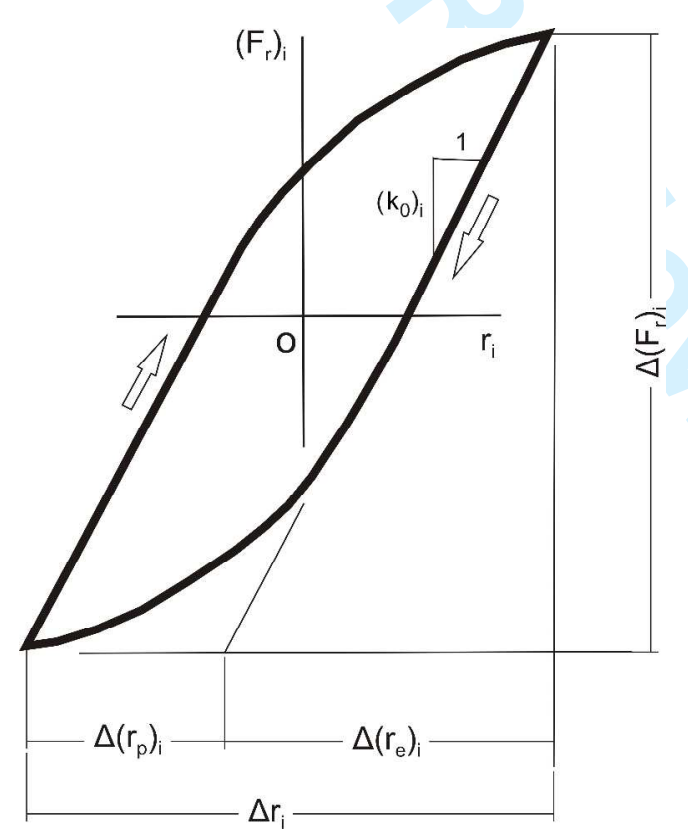

Figure 1. Stable force-displacement hysteresis loop

where, $\Delta r_{i}(t)$ and $\Delta\left(r_{e}\right)_{i}(t)$ are the total and elastic displacement ranges of storey $i$ relative to storey $i-1$ during the same hysteresis loop, respectively. Moreover, 
$\Delta\left(F_{r}\right)_{i}(t)$ is the restoring force range of the loop, $\left(k_{0}\right)_{i}$ is the linear elastic stiffness of $i^{\text {th }}$ storey, and $N$ is the degrees of freedom of the structure. $\Delta\left(F_{r}\right)_{i}(t)$ in Equation (21) can be written using the Bouc-Wen model [17, 18, 21]:

$$
\Delta\left(F_{r}\right)_{i}(t)=\alpha_{i} \frac{\left(F_{y}\right)_{i}}{Y_{i}} \Delta r_{i}(t)+\left(1-\alpha_{i}\right)\left(k_{0}\right)_{i} \Delta h_{i}(t), i=1, \ldots, N
$$

where $\left(F_{y}\right)_{i}, Y_{i}$, and $\alpha_{i}$ are the yield force, the yield displacement, and the bilinear factor of storey $i$, respectively, and $\Delta h_{i}(t)$ is the hysteretic displacement change during the loop. Substituting $\Delta\left(F_{r}\right)_{i}(t)$ in Equation (21) with its equivalent from Equation (22) yields:

$$
\Delta\left(r_{p}\right)_{i}(t)=\frac{\Delta r_{i}(t)-\Delta h_{i}(t)}{1+\left(\frac{\alpha_{i}}{1-\alpha_{i}}\right)}, i=1, \ldots, N
$$

For structures with symmetric hysteresis loops with respect to tension and compression, this equation can be written using half of the ranges or amplitudes:

$$
\left(r_{p}\right)_{i}(t)=\frac{r_{i}(t)-h_{i}(t)}{1+\left(\frac{\alpha_{i}}{1-\alpha_{i}}\right)}, i=1, \ldots, N
$$

Therefore, $\left(x_{p}\right)_{i}(t)$, the absolute plastic displacement of storey $i$ can be calculated as sum of the relative plastic displacements of the first $i$ stories:

$$
\left(x_{p}\right)_{i}(t)=\sum_{i=1}^{i}\left(r_{p}\right)_{i}(t), i=1, \ldots, N
$$


$\left(x_{p}\right)_{i}(t)$ is the deflection of the structure if the elastic component of displacement were removed. It is a function of time, and is zero for an elastically responding structure. Importantly, permanent deflection is typically defined as the final plastic deflection. Plastic displacements over time along with material specific fatigue life curves thus provide greater information and a potential new approach to assessing damage, or basis for remaining structure life. 


\section{ADAPTIVE LMS FILTERING}

Adaptive filters are digital filters with coefficients that can change over time. The general idea is to update filter coefficients and assess how well the existing coefficients are performing in modelling a noisy signal, and then adapt the coefficient values to improve performance. The least mean squares algorithm is a widely used adaptive filtering technique and approximates the Steepest Descent Method using an estimator of the gradient (stochastic-gradient) instead of its actual value, considerably simplifying the calculations for realtime applications. In this case, the goal is to identify the individual scalar $\hat{\alpha}_{i}$ elements by modelling the signal $\{y\}_{k}$ of Equation (20) using the adaptive LMS filter.

In adaptive LMS filtering, the coefficients are adjusted from sample-tosample to minimize the Mean Square Error (MSE), between a measured scalar signal and its modelled value from the filter.

$$
e_{k}=y_{k}-W_{k}^{T} X_{k}=y_{k}-\sum_{i=o}^{m-1} w_{k}(i) x_{k-i}
$$

where $W_{k}$ is the adjustable filter coefficient vector or weight vector at time $k, y_{k}$ is the measured scalar signal at time $k$, to be modelled or approximated, $X_{k}$ is the input vector to the filter, model of current and previous filter inputs, $x_{k-i}$, so $W_{k}^{T} X_{k}$ is the vector dot product output from the filter at time $k$ to model a scalar signal $y_{k}$, and $m$ is the number of prior time steps or taps considered. The Widrow-Hopf LMS algorithm for updating the weights to minimize the error, $e_{k}$, is defined [22]: 


$$
W_{k+1}=W_{k}+2 \mu e_{k} X_{k}
$$

where $\mu$ is a user-selected positive scalar, called step size, that controls the stability and rate of convergence. Several similar stochastic-gradient methods can be used to improve stability and convergence at different computational costs [23].

To identify $\Delta \overline{\mathbf{K}}_{\mathrm{T}}$ at time $k$, using LMS adaptive filters, the One-Step method [3] and Equation (26) in matrix form can be used. Substituting $W_{k}^{T} X_{k}$ with its equivalent from Equation (20), yields:

$$
\{e\}_{k}=\{y\}_{k}-\sum_{j=0}^{m-1} \sum_{i=1}^{n} \hat{\alpha}_{i j} \mathbf{K}_{\mathbf{i}} \cdot\{\Delta \bar{v}\}_{k}
$$

Minimizing the MSE with respect to $\hat{\alpha}_{i j}$ using Equation (27) yields the following weight update formula for each coefficient in the weight matrix of the SHM problem:

$$
w_{k+1}=w_{k}+2 \mu\{e\}_{k}^{T} \mathbf{K}_{\mathbf{i}} \cdot\{\Delta \bar{v}\}_{k-j}
$$

Summing $\hat{\alpha}_{i j}$ over $j$ filter taps, yields the $\hat{\alpha}_{i}$ change in stiffness of each story in Equation (20). The subscript $k-j$ in Equation (29) represents the contribution of prior time step inputs in updating filter weights. 


\section{IDENTIFICATION OF THE BOUC-WEN PARAMETERS}

To identify the Bouc-Wen parameters for any given structure, a two-step procedure is proposed. First, based on limited a priori knowledge of the structure, such as mass, estimated linear damping ratio, and $n_{i}$, the power factor of each storey, push-over finite element analysis (FEA) is done to obtain estimates of $\alpha_{i}, Y_{i}$, and $F_{y}$, the bi-linear factor, the yield displacement, and the yield force of stories, respectively. The second step, which can be done off-line or on-line as an event occurs, yields the basic Bouc-Wen hysteresis loop parameters $\left(A_{i}, \beta_{i}\right.$, and $\left.\gamma_{i}\right)$.

To identify the basic loop parameters, Equation (19) can be written:

$$
\beta_{i} \operatorname{sign}\left(\dot{r}_{i}(t) h_{i}(t)\right)+\gamma_{i}-A_{i}\left|\frac{h_{i}(t)}{Y_{i}}\right|^{-n_{i}}=\frac{h_{i}(t)-h_{i}(t+\Delta t)}{\dot{r}_{i}(t) \Delta t}\left|\frac{h_{i}(t)}{Y_{i}}\right|^{-n_{i}}, i=1, \ldots, N
$$

Therefore,

$$
\begin{cases}\gamma_{i}+\beta_{i}+A_{i} Q(t)=P(t) & \dot{r}_{i}(t) h_{i}(t)>0 \\ \gamma_{i}+A_{i} Q(t)=P(t) & \dot{r}_{i}(t) h_{i}(t)=0 \\ \gamma_{i}-\beta_{i}+A_{i} Q(t)=P(t) & \dot{r}_{i}(t) h_{i}(t)<0\end{cases}
$$

where,

$$
\begin{gathered}
P(t)=\frac{h_{i}(t)-h_{i}(t+\Delta t)}{\dot{r}_{i}(t) \Delta t}\left|\frac{h_{i}(t)}{Y_{i}}\right|^{-n_{i}} \\
Q(t)=-\left|\frac{h_{i}(t)}{Y_{i}}\right|^{-n_{i}}
\end{gathered}
$$


In Equations (31)-(33), $\dot{r}_{i}(t)$, relative velocity between stories $i$ and $i$-1, is calculated using measured velocities of the stories, $Y_{i}$ is known from the FEA, and the hysteretic displacement, $h_{i}(t)$, is then calculated from Equation (34) assuming zero initial values for the hysteretic displacements [24]:

$$
\left\{\begin{array}{l}
\ddot{r}_{i}(t)-\left(1-\delta_{i 1}\right) \frac{q_{i-1}}{m_{i-1}}+\frac{q_{i}}{m_{i}}\left[1+\left(1-\delta_{i 1}\right) \frac{m_{i}}{m_{i-1}}\right]-\left(1-\delta_{i n}\right) \frac{q_{i+1}}{m_{i+1}}\left(\frac{m_{i+1}}{m_{i}}\right)=-\delta_{i 1} \ddot{x}_{g}(t) \\
q_{i}\left(\dot{r}_{i}, r_{i}, h_{i}\right)=c_{i} \dot{r}_{i}(t)+\alpha_{i} \frac{\left(F_{y}\right)_{i}}{Y_{i}} r_{i}(t)+\left(1-\alpha_{i}\right)\left(F_{y}\right)_{i} h_{i}(t) \\
i=1, \ldots, N
\end{array}\right.
$$

where $q_{i}$ is the nonlinear hysteretic restoring force, $m_{i}$ is mass, $c_{i}$ is the equivalent viscous damping, $\left(F_{y}\right)_{i}$ is the yield force, $Y_{i}$ is the yield displacement, and $\alpha_{i}$ is the bi-linear factor, all for storey $i$. Finally, $r_{i}(t), \dot{r}_{i}(t)$, and $\ddot{r}_{i}(t)$ are relative displacement, velocity, and acceleration between storeys $i$ and $i-1$, respectively, $\ddot{x}_{g}(t)$ is the ground acceleration, and $\delta_{i j}$ is the Kronecker delta:

$$
\delta_{i j}=\left\{\begin{array}{l}
1, i=j \\
0, i \neq j
\end{array}\right.
$$

In Equation (34), all of the terms are either known or measured. Hence, it yields a set of independent equations for each storey. These equations can be solved for $h_{i}(t)$ sample-by-sample in real-time. 
For the simpler case of a SDOF shear-type nonlinear hysteretic structure, the equation of motion is written:

$$
m \ddot{v}(t)+c \dot{v}(t)+\alpha \frac{F_{y}}{Y} v(t)+(1-\alpha) F_{y} h(t)=-m \ddot{x}_{g}
$$

where $\ddot{v}(t), \dot{v}(t)$, and $v(t)$ are acceleration, velocity, and displacement of the structure, respectively, $m$ is mass, and $c$ is the equivalent viscous damping of the structure. $F_{y}, Y$, and $\alpha$ are again the yield force, the yield displacement, and the bi-linear factor of the structure. Using Equation (36), $h(t)$ for a SDOF structure can be written:

$$
h(t)=\frac{m\left(\ddot{x}_{g}+\ddot{v}(t)\right)+c \dot{v}(t)}{(\alpha-1) F_{y}}+\frac{\alpha}{\alpha-1} \frac{v(t)}{Y}
$$

Therefore, Equations (31)-(33), using Equations (34) and (35), or in a SDOF case using (36) and (37), provide three independent equations that yield $A_{i}, \beta_{i}$ and $\gamma_{i}$ in less than one hysteresis loop time. This time period is illustrated in Figure 2 for a SDOF hysteretic structure oscillating at $0.5 \mathrm{~Hz}\left(T_{n}=2.0\right.$ seconds) with unit amplitude. In this figure, points where the sign of $\dot{r}_{i}(t) h_{i}(t)$ changes are shown with black dots. As the figure shows, in one quarter of a loop period ( 0.5 seconds), the first three points provide enough independent equations to obtain the three unknown parameters. 


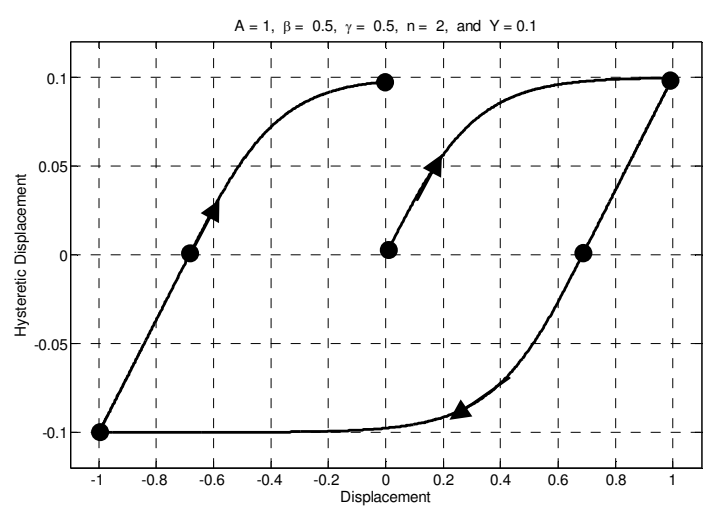

(a)

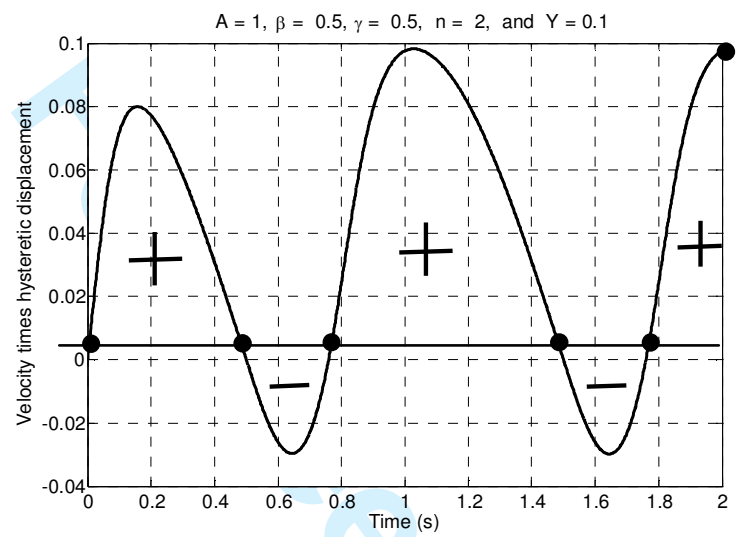

(b)

Figure 2. a) Hysteresis loop for one period of oscillation of a harmonic oscillator at $0.5 \mathrm{~Hz}$ $\left(T_{n}=2.0 \mathrm{~s}\right)$ with unit amplitude, and b) velocity times hysteretic displacement for the same oscillator over the same period.

In this paper, the proposed two-step structural identification method is presented as an on-line technique to first identify the Bouc-Wen model parameters over the first hysteresis loop time assuming no damage to the structure over this short period. The identified hysteretic parameters are then used for structural damage detection. One may also use this method as an offline structural identification technique to obtain the Bouc-Wen parameters using available earthquake records prior to the damage detection, but off-line identified models are not necessarily exact for excitations apart from the 
identification excitation. This choice would impose an added error on the damage detection results when subsequently employed.

The proposed identification method is based on a priori knowledge from the structure, therefore, limitations on the availability of the design data limits the use of the method. In such cases, there are number of more computationallyintensive off-line and on-line identification techniques that can be used. Examples of such methods are least squares [12], Kalman filtering [25], genetic algorithm [21], and bootstrap filtering technique [8].

\section{INPUTS TO THE SHM PROBLEM}

Inputs to this SHM problem are measured structural responses: acceleration, velocity, and displacement. Acceleration can be easily measured with low cost accelerometers at high sampling rates. Due to practical constraints, direct, especially high rate measurement of displacement and velocity is not typically possible. Estimation by integrated measured accelerations is subject to correctable drift and error [26, 27], and other estimations are available. Emerging high speed displacement sensors allow more precise estimation of the velocity at minimal added computational cost and enable this approach [28].

\section{SIMULATED PROOF-OF-CONCEPT STRUCTURE}

The simulated proof-of-concept structure is a SDOF moment-resisting frame model of a five-story concrete building, chosen for both realism and simplicity. The plan view of a typical floor of the building is shown in Figure 3. The floor system consists of 200 series precast hollow-core floor units having a $65 \mathrm{~mm}$ topping spanning on long direction of each floor. The seismic weight per 
floor is $1692 \mathrm{kN}$ for roof level and $2067 \mathrm{kN}$ for other levels. Each storey has $3.8 \mathrm{~m}$ height, and the frame system is designed according to the New Zealand Concrete Structures Standard [29] using the displacement-based design approach to sustain a target drift level of $2 \%$ under a 500 -year return period earthquake.

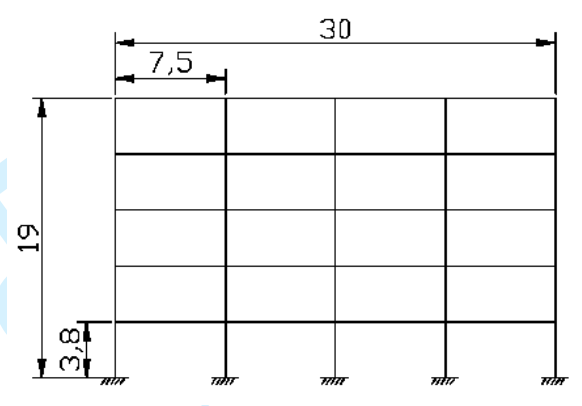

(a)

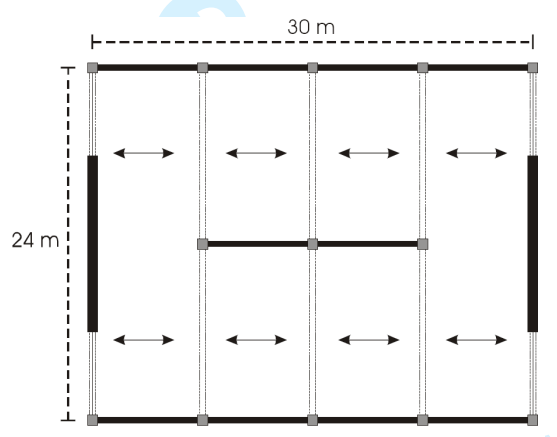

(b)

Figure 3. The simulated 5-storey shear-type concrete building, (a) front view and (b) plan view.

The proposed two-step structural identification method is implemented to identify the Bouc-Wen hysteretic model parameters. To simulate structural responses to be used for the identification, $A=1$ and $\beta=\gamma=0.5$ are used, and the structure is subjected to the El Centro earthquake. Nonlinear dynamic analysis is performed in MATLAB ${ }^{\circledR}$ using the identified parameters to represent the nonlinear hysteretic behaviour of the structure. The simulated structural responses from MATLAB ${ }^{\circledR}$ are used to provide proof of concept and quantify 
the accuracy of the identified parameters, changes in linear elastic stiffness of each storey, plastic and permanent displacements. In simulating the structural responses, 5\% constant viscous damping is considered, and the building was given an abruptness or power factor of $\mathrm{n}=2$ to provide realistic nonlinear structural behaviour.

The developed SHM algorithm is implemented in MATLAB ${ }^{\circledR}$ for the stiffness identification process. Identified values were used to recalculate structural responses using the Newmark- $\beta$ integration method to assess accuracy. The simulated structure was subjected to the Cape Mendocino record with peak ground acceleration (PGA) of $0.23 \mathrm{~g}$, with a $10 \%$ reduction in preyield stiffness applied to the structure at the 10 second mark to simulate sudden damage, and simulation-derived data is recorded at $500 \mathrm{~Hz}$.

Next, to assess the robustness of the proposed method over different ground motions, the simulated structure was subjected to a suite of 20 different ground motions shown in Table 1. The same identified hysteretic parameters were used for all of the records, and a 5\% reduction in pre-yield stiffness was applied to the structure at the 10 second mark. This small amount of damage is chosen to show the capability of the proposed algorithm in capturing small levels of damage. The adaptive identification process was performed with a fixed filter tuning parameter or step size $(\mu)$ for all of the records in Table 1. This factor determines the speed of convergence. Simulation-derived data again is recorded at $500 \mathrm{~Hz}$.

More details about the selected records can be found in [30]. This suite has been selected since it has been widely used for structural dynamic analyses in different studies and is a very popular suite among earthquake engineers. 


\section{RESULTS}

\subsection{Hysteretic model parameters identification results}

Figure 4 shows the push-over analysis results for the proof-of-concept structure from Ruaumoko [31]. It shows total yield force $(1269.45 \mathrm{kN})$, bi-linear factor (0.065), and yield displacement $(46.5 \mathrm{~mm})$. These parameters are used for the second step of the identification process to obtain $A, \beta$, and $\gamma$, the basic hysteresis loop parameters of the proof-of-concept structure. Figure 5 shows that the hysteretic parameters $(A, \beta$, and $\gamma)$ can be identified in less than a quarter of the natural period of the structure ( 0.3 seconds in this case).

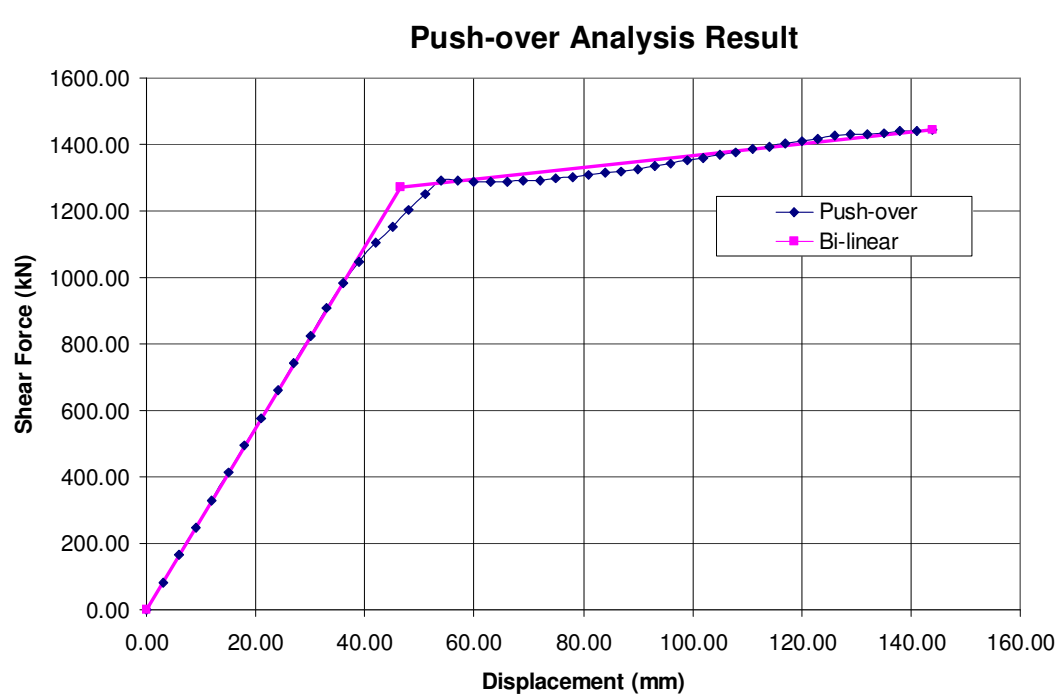

Figure 4. Push-over analysis results of the simulated building using the Ruaumoko finite element code [31]. 
Figure 5. Identified hysteretic parameters for the simulated case-study structure subjected to the El Centro earthquake.

\subsection{Damage identification results}

Figure 6 shows the response of the SDOF model with a 10\% reduction in the linear elastic stiffness at 10 seconds for the Cape Mendocino earthquake. As shown in Figure 7, in a worst-case sudden failure situation, $\Delta k_{0}$, the changes in pre-yield linear elastic stiffness of the structure, converge to within $10 \%$ of the actual change in value in less than 2 seconds using 10 filter taps at a $500 \mathrm{~Hz}$ sampling rate. Figure 8 shows that filter approaches faster and smoother to the final values of the pre-yield stiffness changes after damage when higher sampling rates or a greater number of taps (or prior time steps) are used. 

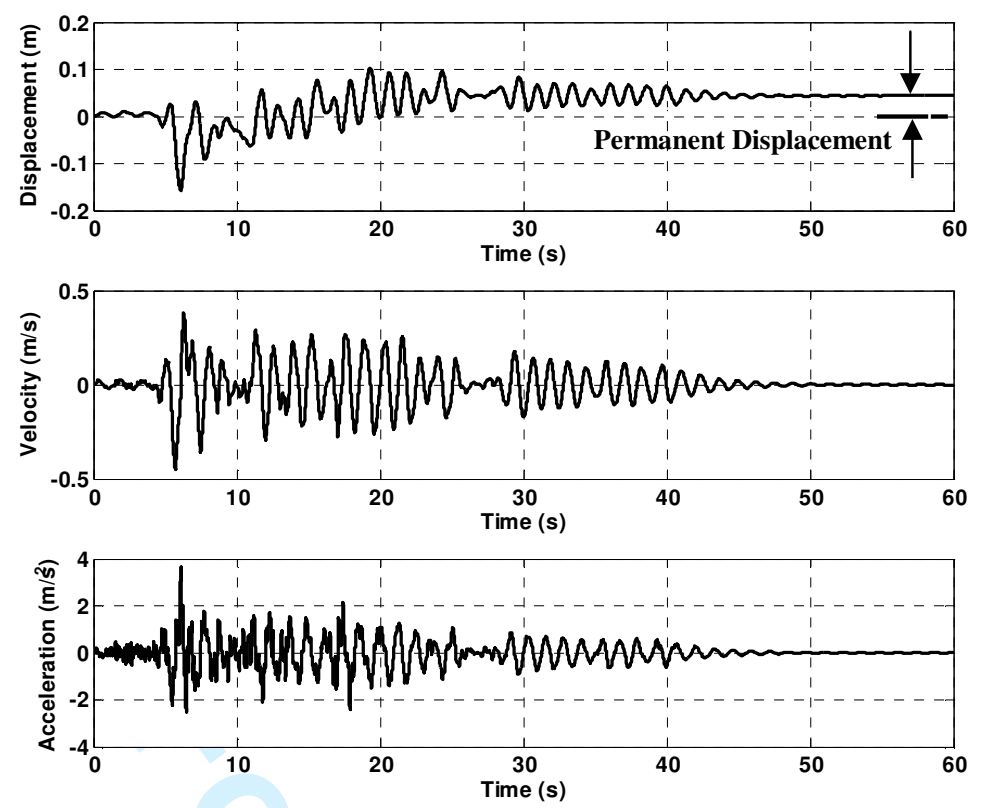

Figure 6. Responses of the simulated structure subject to the Cape Mendocino earthquake and $10 \%$ sudden failure at the 10 second mark.

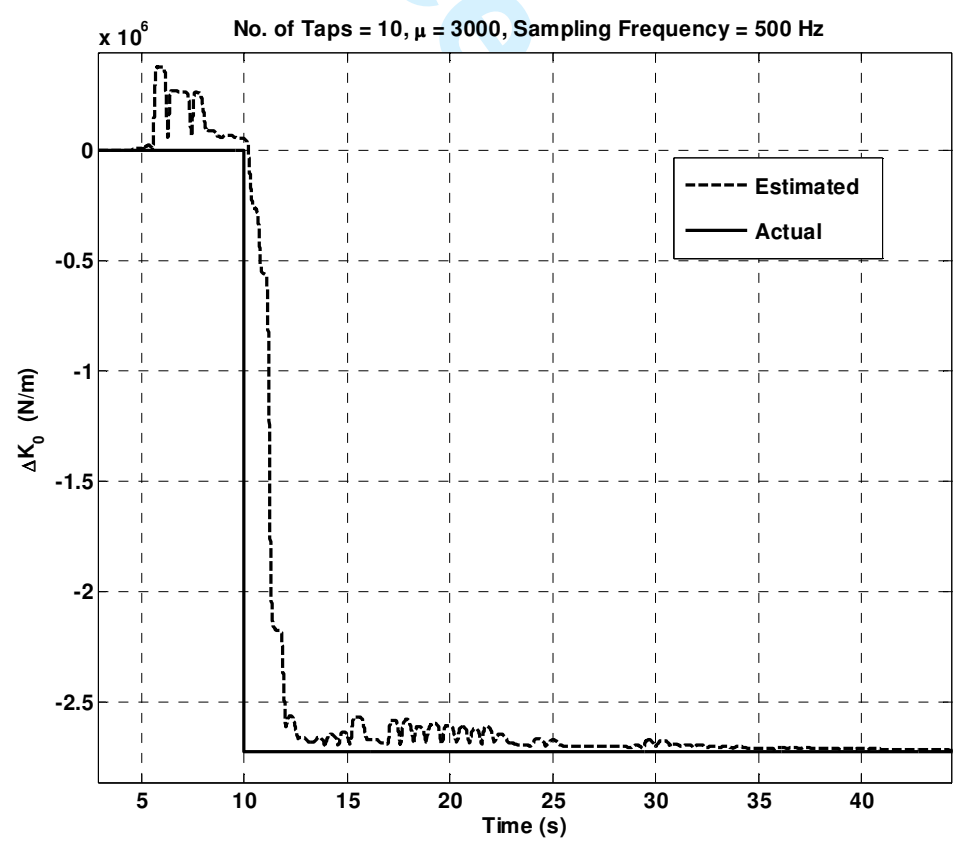

Figure 7. Identified changes in pre-yield stiffness of the simulated structure with $10 \%$ sudden failure using adaptive LMS algorithm. 


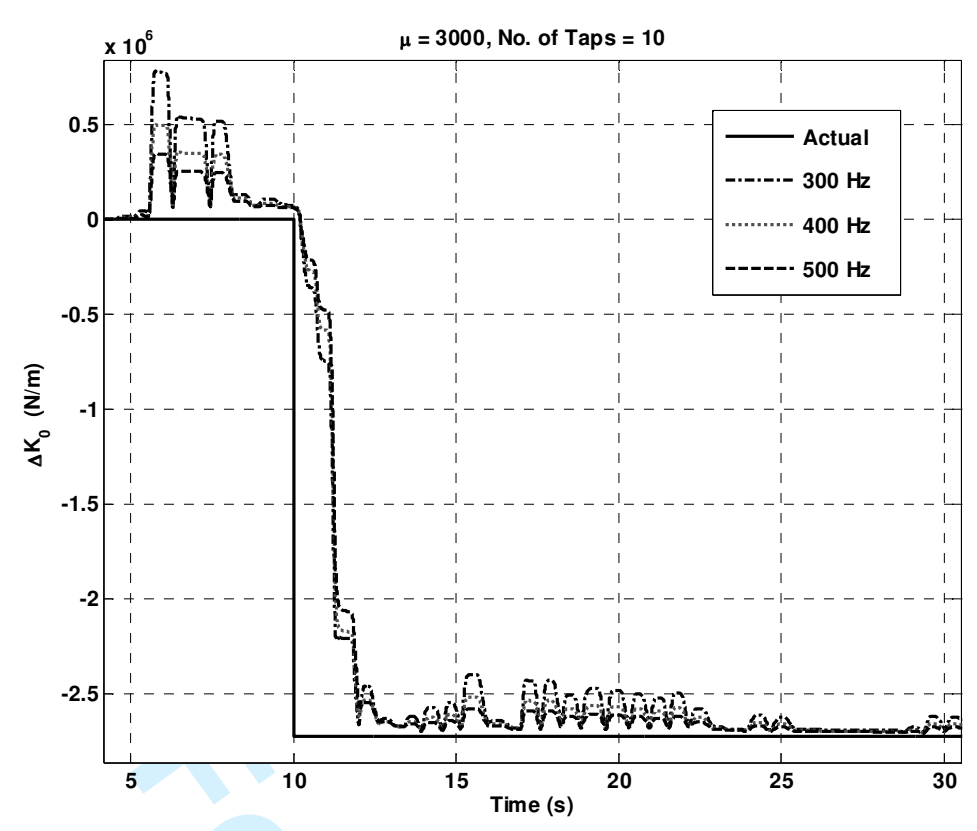

(a)

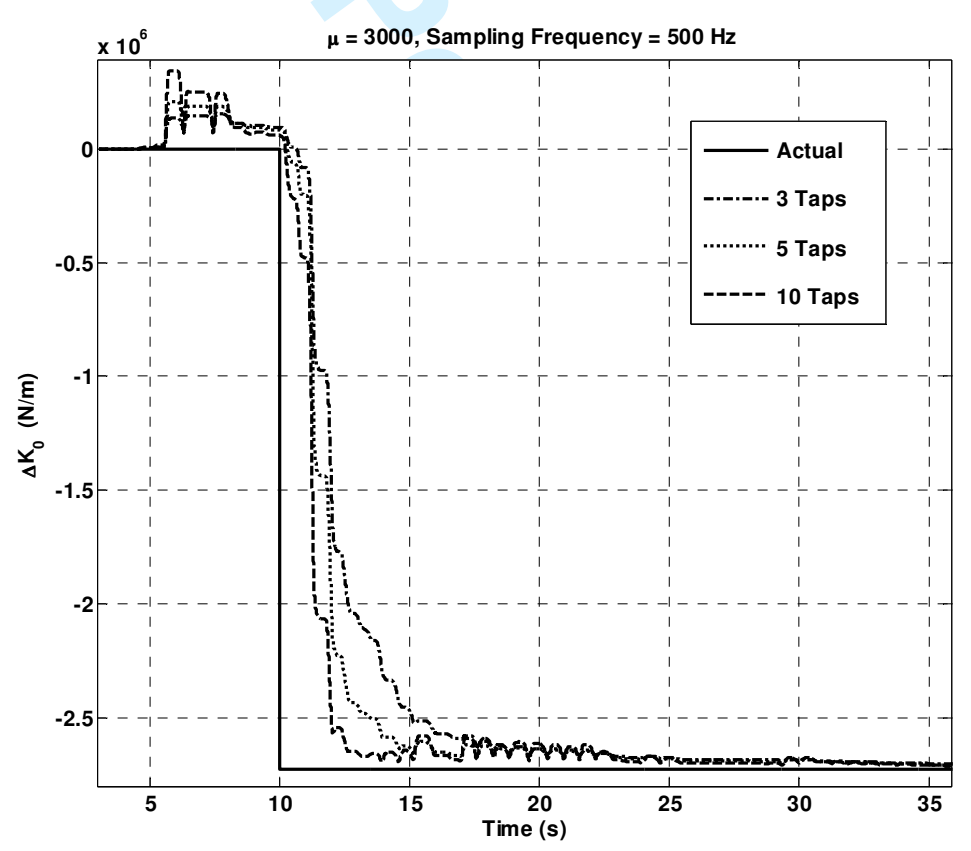

(b)

Figure 8. Identified changes in pre-yield stiffness of the simulated structure with $10 \%$ sudden failure using adaptive LMS algorithm, (a) at different sampling rates and (b) with different tap numbers. 
Figure 9 shows the nonlinear structure re-simulation results using Equation (20) and Newmark- $\beta$ with the identified values for the hysteretic parameters and changes in stiffness $\left(\Delta k_{0}\right)$. This figure clearly shows that as sudden change occurs, plastic deflection begins in this case. The model then tracks the initial sampled behaviour accurately. For the entire record, the ratio between the norm of the error signal in estimating the plastic deflections and the norm of the actual plastic deflection signal is less than $2.5 \%$, and error in identifying permanent deflection is less than $0.5 \%$ of the actual value. 


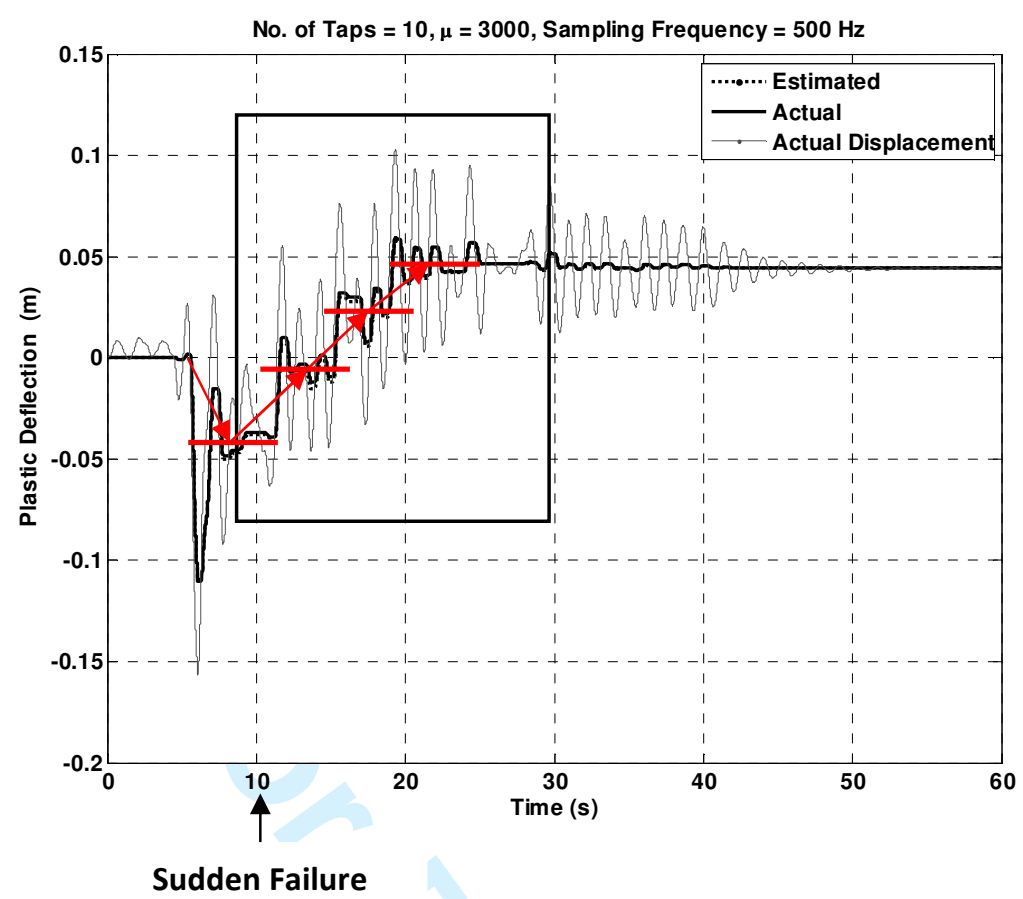

(a)

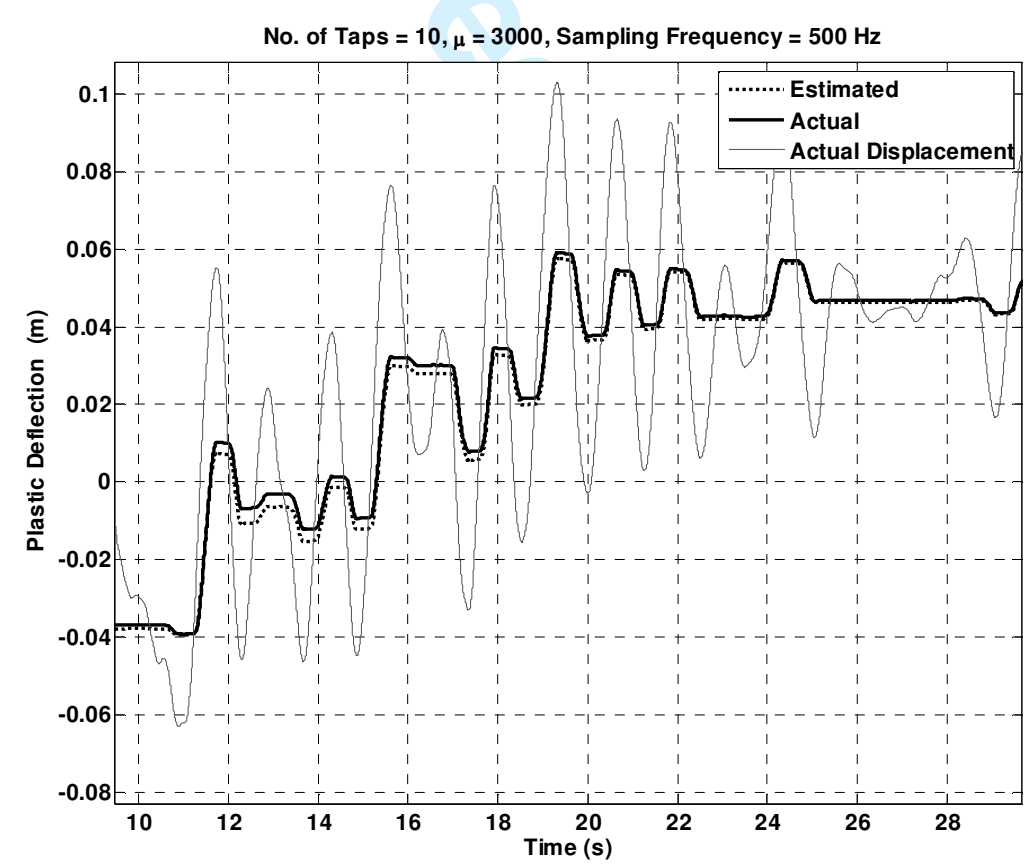

(b)

Figure 9. Identified plastic displacements of the simulated structure with $10 \%$ sudden failure at the time of 10 second mark using the estimated changes in pre-yield stiffness. The box in panel (a) shows the area highlighted in panel (b). 


\subsection{External load effect on damage identification results}

Figure 10 shows, in a worst-case sudden failure situation, $\Delta \mathrm{k}_{0}$ converges to within $10 \%$ of the actual value in less than 2 seconds using a fixed step size and 10 taps at a $500 \mathrm{~Hz}$ sampling rate under all 20 different excitations in Table 1. Once more, re-simulating the structure with the identified values shows that as the filter converges, the plastic deflection approaches its actual value and the errors between the actual and estimated values for plastic deflections become smaller. For the suite used in this study, Figures 11-12 show the ratio between norms of the error signal in estimating the plastic deflections and the actual plastic deflection signal is less than $12 \%$, and the error in identifying permanent deflection is less than $15 \%$ of the actual value over the entire records. Records that caused permanent deflections less than $0.1 \%$ of the height of the case study structure were excluded from the error summary and set to zero due to their very small size and insignificance.

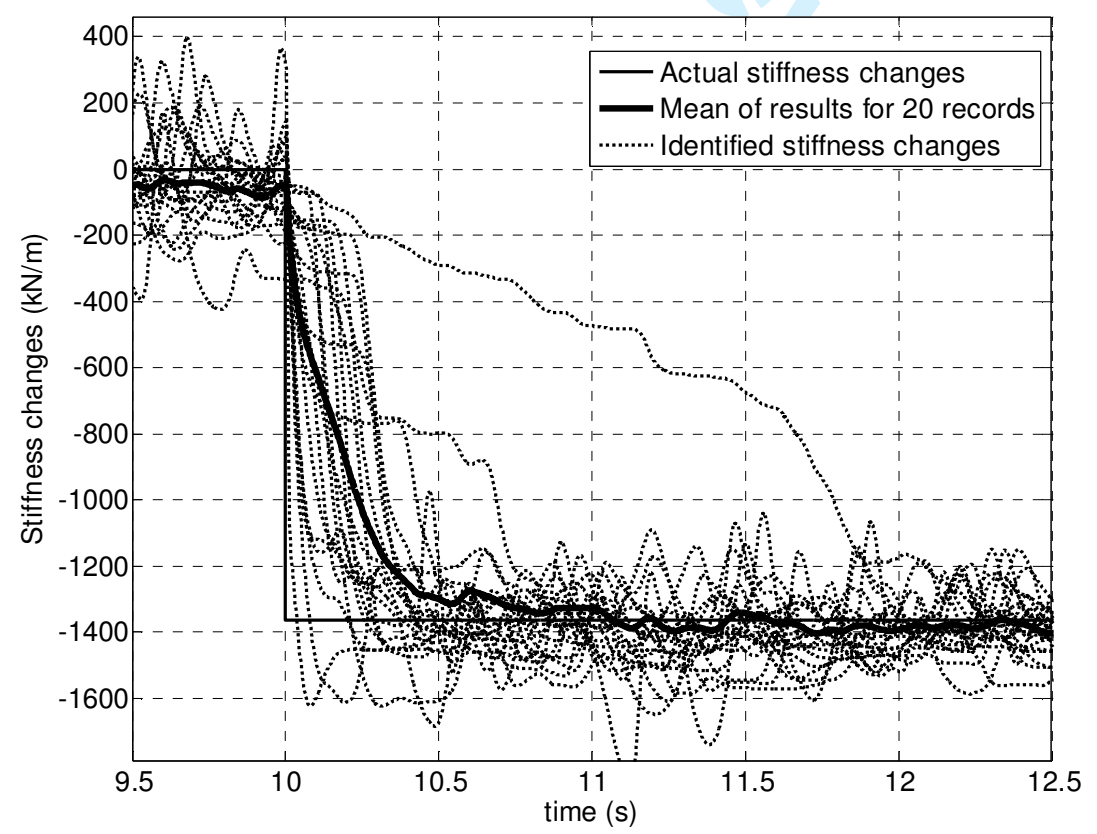

Figure 10. Identified changes in linear elastic stiffness of the simulated structure 
(10 taps with $\mu=25000$ ).

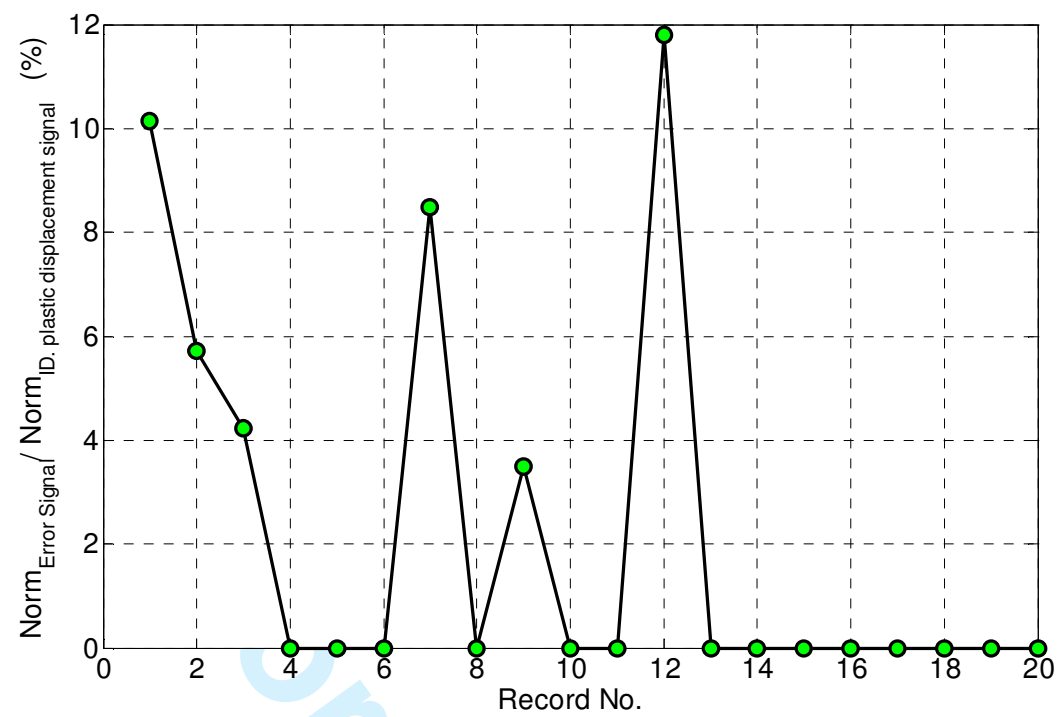

Figure 11. Changes in ratio of norms of the error in identifying plastic deflections and plastic deflection signal for 20 different records in Table 1 (Mean=7.31\%, Median=7.1\%, and $\operatorname{IQR}=5.93 \%)$.

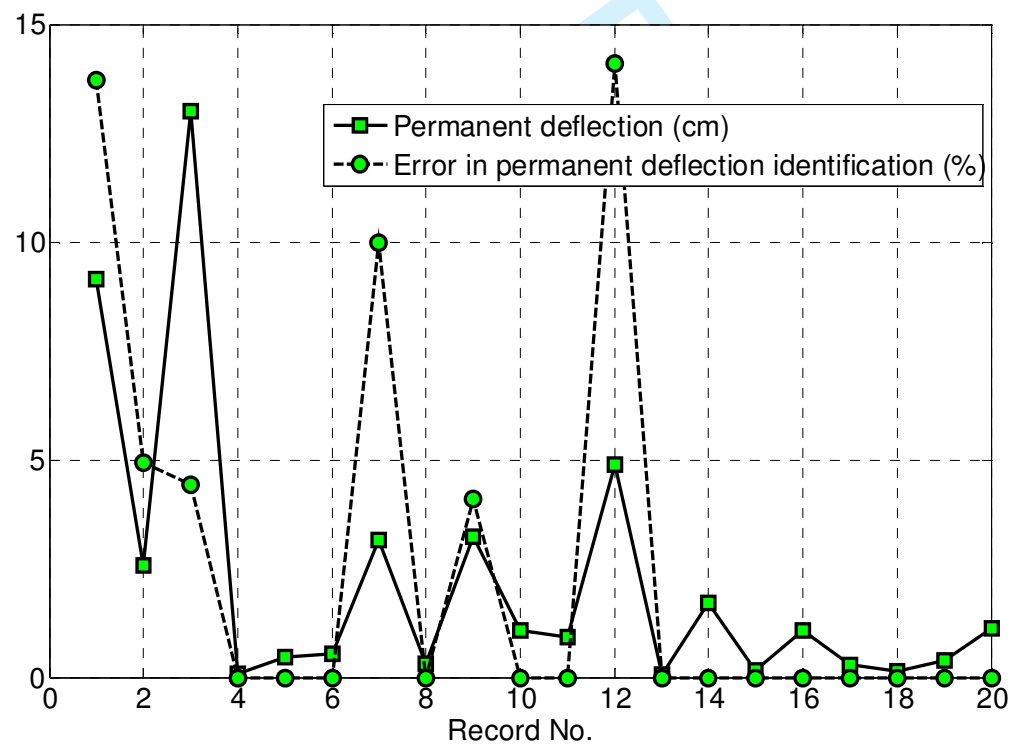

Figure 12. Identified permanent deflection and permanent deflection identification error for the 20 different records in Table 1 (Mean error=8.54\%, Median error=7.46\%, and $I Q R=9.3 \%$ ). 
Figures 10-12 show that performance of the proposed SHM algorithm in identifying changes in stiffness and plastic or permanent deflections changes for different ground excitations. Thus, for fixed filter tuning parameters, some cases result in fairly large errors as high as $14 \%$ in identified permanent deflection. This problem can be solved to some extent by implementing a variable step-size or self-tuning LMS-based filtering algorithm initially tuned based on past earthquake records and capable of self-tuning to external load changes for the best identification results. Different methods with variable step-size can be found in the adaptive filtering literature to improve the identification results [23]. However, most of the results here are less than 5\%, and even the largest errors are broadly acceptable.

It is worth mentioning that the accuracy of any model-based SHM algorithm relies directly on the correctness and thoroughness of its baseline model, which is the Bouc-Wen model in this case. Therefore, using a more comprehensive baseline model and having more precise estimation of the baseline model parameters would yield more accurate results. These analyses were not included in this first presentation of the algorithm, but present a future avenue of research.

\section{CONCLUSIONS}

This research developed a LMS-based SHM method with a baseline nonlinear Bouc-Wen structural model that can directly identify changes in stiffness and plastic deflections in real-time. Proof-of-concept simulation results show that for simulated SDOF structure and suite of records considered, the algorithm identifies stiffness changes to within $10 \%$ of true values in less than 2.0 seconds, and permanent deflection is identified to within $14 \%$ of actual 
values using noise-free structural responses. The algorithm is thus robust to ground motion excitation and these results could be readily improved with a more optimized adaptive filter. This proof-of-concept analysis and research thus show that:

- Computationally simple adaptive filtering method can be readily extended to accurately identify plastic and permanent deflections in real-time.

- The two-step method presented thus offers significant potential benefit in assessing structural damage, serviceability, and safety after a major event that was not previously possible.

Overall, these methods remain to be experimentally proven and further tested, but are both a first step forward and can be readily generalized to other similar nonlinear models.

\section{ACKNOWLEDGEMENTS}

Authors would like to thank Mr. Julian Murphy and Mr. Rodney Elliott, technical officers in the Mechanical Engineering Department at the University of Canterbury, Mr. Sayuj Nath from National Instruments-New Zealand, and Mr. Masoud Moghaddasi, PhD candidate in the Civil Engineering Department at the University of Canterbury, for their invaluable comments on the experimental set-up, high-speed image acquisition, and earthquake record selection.

\section{REFERENCES}

1. Doherty, J.E., Non-destructive evaluation, in Handbook on Experimental Mechanics, A.S. Kobayashi, Editor. 1987, Prentice-Hall, Inc.: Englewood Cliffs, NJ.

2. Doebling, S.W., et al., Damage identification and health monitoring of structural and mechanical systems from changes in their vibration characteristics: a literature review. 1996, Los Alamos National Laboratory 
3. Chase, J.G., et al., A simple LMS-based approach to the structural health monitoring benchmark problem. Earthquake Engineering \& Structural Dynamics, 2005. 34(6): p. 575-594.

4. Hou, Z., M. Noori, and R.S. Amand, Wavelet-Based Approach for Structural Damage Detection. Journal of Engineering Mechanics, 2000. 126(7): p. 677-683.

5. Loh, C.-H., C.-Y. Lin, and C.-C. Huang, Time Domain Identification of Frames under Earthquake Loadings. Journal of Engineering Mechanics, 2000. 126(7): p. 693-703.

6. Sato, T. and K. Takei. Real time robust identification algorithm for structural systems with time-varying dynamic characteristics. in Proceedings of SPIE: Smart Structures and Materials, Mathematics and Control in Smart Structures 1997. San Diego, CA, USA.

7. Sato, T. and K. Qi, Adaptive $H_{\infty}$ Filter: Its Application to Structural Identification. Journal of Engineering Mechanics, 1998. 124(11): p. 1233-1240.

8. Li, S.J., Y. Suzuki, and M. Noori, Improvement of parameter estimation for non-linear hysteretic systems with slip by a fast Bayesian bootstrap filter. International Journal of Non-Linear Mechanics, 2004. 39(9): p. 1435-1445.

9. Chassiakos, A.G., et al., On-Line Identification of Hysteretic Systems. Journal of Applied Mechanics, 1998. 65(1): p. 194-203.

10. Smyth, A.W., et al., On-Line Parametric Identification of MDOF Nonlinear Hysteretic Systems. Journal of Engineering Mechanics, 1999. 125(2): p. 133-142.

11. Lin, J.-W., et al., On-line identification of non-linear hysteretic structural systems using a variable trace approach. Earthquake Engineering \& Structural Dynamics, 2001. 30(9): p. 1279-1303.

12. Yang, J.N. and S. Lin, On-line identification of non-linear hysteretic structures using an adaptive tracking technique. International Journal of Non-Linear Mechanics, 2004. 39(9): p. 1481-1491.

13. Chase, J.G., V. Begoc, and L.R. Barroso, Efficient structural health monitoring for a benchmark structure using adaptive RLS filters. Computers \& Structures, 2005. 83(89): p. 639-647.

14. Chase, J.G., et al., LMS-based structural health monitoring of a non-linear rocking structure. Earthquake Engineering \& Structural Dynamics, 2005. 34(8): p. 909-930.

15. Bouc, R. Forced vibration of mechanical systems with hysteresis. in The 14th Conference on Non-Linear Oscillation. 1967. Prague, Czechoslovakia.

16. Wen, Y.-K., Method for random vibration of hysteretic systems. Journal of Engineering Mechanics Division, ASCE, 1976. 102(2): p. 249-263.

17. Constantinou, M. and I. Tadjbakhsh, Hysteretic dampers in base isolation: random approach. Journal of Structural Engineering, ASCE, Apr. 1985. 111(4): p. 705-721.

18. Ismail, M., F. Ikhouane, and J. Rodellar, The hysteresis Bouc-Wen model, a survey. Archives of Computational Methods in Engineering, 2009. 16(2): p. 161-188.

19. Baber, T. and M. Noori, Modelling general hysteresis behaviour and random vibration application. Journal of Vibration, Acoustics, Stress, and Reliability in Design, 1986. 108: p. 411-420.

20. Dowling, N.E., Mechanical Behavior of Materials: Engineering Methods for Deformation, Fracture, and Fatigue Third ed. 2007, New Jersey: Pearson Prentice Hall.

21. Ma, F., C.H. Ng, and N. Ajavakom, On system identification and response prediction of degrading structures. Structural Control and Health Monitoring, 2006. 13(1): p. 347364.

22. Ifeachor, E.C. and B.W. Jervis, Digital signal processing: A practical approach. 1993: Addison-Wesley.

23. Sayed, A.H., Fundamentals of Adaptive Filtering. 2003: John Wiley \& Sons, Inc.

24. Baber, T. and Y.-K. Wen, Random vibration of hysteretic, degrading systems. Journal of Engineering Mechanics Division, ASCE, Dec. 1981. 107(EM6): p. 1069-1087.

25. Zhang, H., et al., Parameter identification of inelastic structures under dynamic loads. Earthquake Engineering \& Structural Dynamics, 2002. 31(5): p. 1113-1130.

26. $\mathrm{Li}, \mathrm{X}$., et al. Integration of GPS, accelerometer and optical fibre sensors for structural deformation monitoring. in the 17th International Technical Meeting of the Satellite Division of the Institute of Navigation ION GNSS. 21-24 Sep, 2004. Long Beach, California

27. Hann, C.E., et al., Real-Time System Identification of a Nonlinear Four-Story Steel Frame Structure-Application to Structural Health Monitoring. Sensors Journal, IEEE, 2009. 9(11): p. 1339-1346. 
1

2

3

4

5

6

7

8

9

10

11

12

13

14

15

16

17

18

19

20

21

22

23

24

25

26

27

28

29

30

31

32

33

34

35

36

37

38

39

40

41

42

43

44

45

46

47

48

49

50

51

52

53

54

55

56

57

58

59

60

28. Nayyerloo, M., et al. Seismic structural displacement measurement using a high-speed line-scan camera: experimental validation. in The 2010 New Zealand Society of Earthquake Engineering Conference and AGM. 26-28 March, 2010. Wellington, New Zealand.

29. NZS 3101, Concrete Structures Standard, New Zealand. 2006.

30. Christopoulos, C., A. Filiatrault, and B. Folz, Seismic response of self-centring hysteretic SDOF systems. Earthquake Engineering \& Structural Dynamics, 2002. 31(5): p. 1131-1150.

31. Carr, A.J. RUAUMOKO, program for inelastic dynamic analysis: user manual. 2004. Department of Civil Engineering, University of Canterbury, Christchurch, New Zealand. 
Table 1. Selected ground motions

\begin{tabular}{|c|c|c|c|c|c|c|c|c|}
\hline EQ & Event & Year & Station & $\begin{array}{c}\text { R-Distance } \\
(\mathrm{km})\end{array}$ & Soil Type & $\begin{array}{l}\text { Duration } \\
\text { (s) }\end{array}$ & $\begin{array}{l}\text { Scaling } \\
\text { Factor }\end{array}$ & $\begin{array}{c}\text { PGA } \\
(\mathrm{g})\end{array}$ \\
\hline EQ1 & \multirow{2}{*}{ Cape Mendocino } & \multirow{2}{*}{1992} & Fortuna - Fortuna Blvd. & 23.6 & B & 44.0 & 3.8 & 0.116 \\
\hline EQ2 & & & Rio Dell Overpass - FF & 18.5 & $\mathrm{~B}$ & 36.0 & 1.2 & 0.385 \\
\hline EQ3 & \multirow{2}{*}{ Landers } & \multirow{2}{*}{1992} & Desert Hot Springs & 23.2 & B & 50.0 & 2.7 & 0.171 \\
\hline EQ4 & & & Yermo Fire Station & 24.9 & $\mathrm{C}$ & 44.0 & 2.2 & 0.245 \\
\hline EQ5 & \multirow{6}{*}{ Loma Prieta } & \multirow{6}{*}{1989} & Capitola & 14.5 & $\mathrm{C}$ & 40.0 & 0.9 & 0.48 \\
\hline EQ6 & & & Gilroy Array \#3 & 14.4 & $\mathrm{C}$ & 39.0 & 0.7 & 0.367 \\
\hline EQ7 & & & Gilroy Array \#4 & 16.1 & $\mathrm{C}$ & 40.0 & 1.3 & 0.417 \\
\hline EQ8 & & & Gilroy Array \#7 & 24.2 & $\mathrm{C}$ & 40.0 & 2.0 & 0.323 \\
\hline EQ9 & & & Hollister Diff. Array & 25.8 & - & 39.6 & 1.3 & 0.269 \\
\hline EQ10 & & & Anderson Dam & 21.4 & B & 40.0 & 1.4 & 0.244 \\
\hline EQ11 & \multirow{7}{*}{ Northridge } & \multirow{7}{*}{1994} & Beverly Hills 14145 Mulhol & 20.8 & B & 30.0 & 0.9 & 0.617 \\
\hline EQ12 & & & Canoga Park - Topanga Can & 15.8 & $\mathrm{C}$ & 25.0 & 1.2 & 0.42 \\
\hline EQ13 & & & Glendale - Las Palmas & 25.4 & $\mathrm{C}$ & 30.0 & 1.1 & 0.357 \\
\hline EQ14 & & & LA - Hollywood Stor FF & 25.5 & $\mathrm{C}$ & 40.0 & 1.9 & 0.358 \\
\hline EQ15 & & & LA - N Faring Rd & 23.9 & $\mathrm{C}$ & 30.0 & 2.2 & 0.242 \\
\hline EQ16 & & & N. Hollywood - Coldwater & 14.6 & $\mathrm{~B}$ & 21.9 & 1.7 & 0.298 \\
\hline EQ17 & & & Sunland - Mt Gleason Ave. & 17.7 & $\mathrm{~B}$ & 30.0 & 2.2 & 0.157 \\
\hline EQ18 & \multirow{3}{*}{ Superstition Hills } & \multirow{3}{*}{1987} & Brawley & 18.2 & $\mathrm{C}$ & 22.0 & 2.7 & 0.116 \\
\hline EQ19 & & & El Centro Imp. Co. Cent. & 13.9 & $\mathrm{C}$ & 40.0 & 1.9 & 0.358 \\
\hline EQ20 & & & Plaster City. & 21.0 & C & 22.2 & 2.2 & 0.186 \\
\hline
\end{tabular}

